\title{
Urinary Incontinence in Physically Active Older Women of Northeast Brazil
}

\author{
Thais Sousa Rodrigues Guedes ${ }^{1}{ }^{1}$, Marcello Barbosa Otoni Gonçalves Guedes ${ }^{2}$, \\ Hévila Kilvia Miguel de Oliveira ${ }^{3}$, Rodrigo Lopes Soares ${ }^{3}{ }^{-}$, Vitor Leandro da Cunha ${ }^{4}{ }^{\circ}$, \\ Johnnatas Mikael Lopes ${ }^{5}$, Nayara Priscila Dantas de Oliveira ${ }^{6}\left(\mathbb{D}\right.$, Javier Jerez-Roig ${ }^{7, *(D)}$ \\ and Dyego Leandro Bezerra de Souza ${ }^{7,8}$
}

check for updates

Citation: Guedes, T.S.R.; Guedes, M.B.O.G.; de Oliveira, H.K.M.; Soares, R.L.; da Cunha, V.L.; Lopes, J.M.; de Oliveira, N.P.D.; Jerez-Roig, J.; de Souza, D.L.B. Urinary Incontinence in Physically Active Older Women of Northeast Brazil. Int. J. Environ. Res. Public Health 2021, 18, 5878. https:// doi.org/10.3390/ijerph18115878

Academic Editors: Paul B. Tchounwou and David Berrigan

Received: 1 April 2021

Accepted: 26 May 2021

Published: 30 May 2021

Publisher's Note: MDPI stays neutral with regard to jurisdictional claims in published maps and institutional affiliations.

Copyright: (c) 2021 by the authors. Licensee MDPI, Basel, Switzerland. This article is an open access article distributed under the terms and conditions of the Creative Commons Attribution (CC BY) license (https:// creativecommons.org/licenses/by/ $4.0 /)$.
1 Graduate Program in Health Sciences, Center of Health Sciences, Campus Universitário Lagoa Nova, Federal University of Rio Grande do Norte (UFRN), Natal 59078-970, Brazil; thais.sousarodrigues@gmail.com

2 Department of Physiotherapy, Campus Universitário Lagoa Nova, Federal University of Rio Grande do Norte (UFRN), Natal 59078-970, Brazil; marcelloguedes21@hotmail.com

3 Faculty Mauricio de Nassau, Av. Engenheiro Roberto Freire, Natal 59078-600, Brazil; kilvia.oliveira22@outlook.com (H.K.M.d.O.); contato-rodrigo@outlook.com (R.L.S.)

4 Graduate Program in Neuroengineering, Edmond and Lily Safra International Institute of Neuroscience, Santos Dumont Institute, Macaiba 59280-000, Brazil; vitor.cunha@edu.isd.org.br

5 Department of Medicine, Federal University of Vale do São Francisco (UNIVASF), Paulo Afonso 48605-560, Brazil; johnnataslopes2@gmail.com

6 Graduate Program in Collective Health, Department of Public Health, Federal University of Rio Grande do Norte (UFRN), Natal 59078-970, Brazil; nayoliveira.fisio@gmail.com

7 Research Group on Methodology, Methods, Models and Outcomes of Health and Social Sciences $\left(\mathrm{M}_{3} \mathrm{O}\right)$, Faculty of Health Science and Welfare, Centre for Health and Social Care Research (CESS), University of Vic-Central University of Catalonia (UVic-UCC), 08500 Vic, Barcelona, Spain; dysouz@yahoo.com.br

8 Graduate Program in Health Science, Department of Public Health, Campus Universitário Lagoa Nova, Fed-eral University of Rio Grande do Norte (UFRN), Natal 59078-970, Brazil

* Correspondence: javier.jerez@uvic.cat; Tel.: +34-938-816-025

Abstract: Low- and moderate-impact physical activity (PA) is associated with the prevention of urinary incontinence (UI). The objective of the cross-sectional study presented herein is to analyze the factors associated with UI in physically older active women who participate in senior community groups. The variable UI was measured by the International Consultation Incontinence Questionnaire Short Form (ICIQ-SF). Socioeconomic variables were also collected, along with data on life habits and clinical history. The multivariate analysis employed Poisson's Regression with robust variance for factors associated with UI. Of the 106 participants evaluated, 54.7\% presented UI, of which stress incontinence was more frequent, with $40.6 \%$. UI presented a statistically significant association with dizziness/loss of balance during Activities of Daily Living (ADL) (prevalence ratio-PR 1.48; 95\% CI 1.06-2.07) and nocturia (PR 1.63; 95\% CI 1.05-2.55). Despite PA being a protection factor, UI presented an elevated prevalence in the older population, and therefore, other biological, social, and cultural aspects could also contribute to the occurrence of UI in this age group. Moreover, physically active older women with UI presented nocturia and dizziness/loss of balance during ADL, regardless of education levels and the number of births. These findings can help improve multi-professional programs aimed at promoting, preventing, and managing UI in the public.

Keywords: elderly; loss of bladder control; exercise

\section{Introduction}

The global older population has been increasing significantly by $3 \%$ per year. By 2050, the population will be constituted by approximately 2.1 billion seniors [1]. In Brazil, currently, the proportion of people over 60 years old is $13 \%$, and by 2050 [2], it is estimated that seniors will constitute $29.3 \%$ of the population [3]. In this context, optimization of the 
public services offered to this share of the population is essential, with integral actions and public health policies supported by adequate epidemiological information [4].

Considering the physiological changes that accompany the advance in age, it is important to consider strategies oriented to maintaining quality of life (QL) and promoting older people's health. This can lead to a more independent older population, contributing to better performance and self-confidence when carrying out Activities of Daily Life (ADL). It must be highlighted that healthy aging refers to developing and maintaining a functional capacity so that older people can embrace wellness as a part of everyday life [5]. The term active aging is associated with healthy aging and is used by the World Health Organization (WHO) to refer to the process of optimizing health, participation, and safety opportunities to improve the quality of life [6]. Studies have demonstrated the importance of physical activity (exercise) for good physical conditioning of seniors, leading to improvements in abilities, muscular strength, mobility, flexibility, and cognition, promoting functional improvements that favor good QL in older people [7].

Considering the relevance of practicing physical activities to achieve good structural conditioning during the aging process, it must be noted that the regular practice of exercise is fundamental at all stages of life [8]. Keeping active while aging can be beneficial in promoting good health and preventing some issues, such as urinary incontinence (UI), especially in older women [5].

The International Continence Society defines UI as the complaint of involuntary loss of urine, which affects approximately $25-45 \%$ of the female population throughout life [9]. UI is pointed to as one of the greatest concerns of health professionals, being one of the dysfunctions that most affect women nowadays, causing negative impacts to QL [10].

Studies have pointed out that low- to medium-impact physical exercise can help prevent dysfunctions in the pelvic floor, especially UI [11,12]. It is suggested that physically active women have stronger pelvic floors; also, with the increase in abdominal pressure during physical exercises, there is a reflex contraction of pelvic floor muscles, which contributes to the urinary continence mechanism [11,12]. Therefore, older women can benefit from this strategy.

High-impact physical exercises are described in scientific literature as a risk factor for UI. High impact activities can affect the continence mechanism due to a change in the force transmitted to the pelvic floor, increasing intra-abdominal pressure significantly. These changes compromise the supporting, suspension, and contention mechanisms of the pelvic floor, which suffers intense and repetitive overload, leading to its weakening [13].

UI is a problem that directly affects the QL of older women, either due to functional or psychological limitations that lead to restrictions in social life [14]. The majority of studies on factors associated with UI in physically active older people have been carried out in developed countries, with different socioeconomic and health-related characteristics from the Brazilian Northeast. Therefore, the objective of this study is to identify the factors associated with UI in physically active older women living in Northeast Brazil.

\section{Material and Methods}

Participants and Procedures

This is a quantitative, cross-sectional study with a descriptive approach and inferential analysis. Data collection occurred between September and December 2017. A non-probabilistic sample of older women who practiced regular physical exercise in two community groups of Natal, Northeast Brazil, was obtained. The senior groups were selected for convenience; both offered regular low-impact supervised physical activities, five times a week: hydrogymnastics, dance, and gymnastic routines, for $60 \mathrm{~min}$ each.

The sample size of this study $(n=106)$ enabled the identification of a $17 \%$ difference of proportion, with a confidence level of $95 \%$ and $80 \%$ test power [15]. The inclusion criteria were: women at least 60 years old [6], who practiced physical exercise at least two times a week (any type offered by the community groups). The exclusion criteria were: women with a cognitive deficit preventing the understanding of the questionnaires applied 
during the interviews; women who could not attend the interview; women who, for any reason, did not complete the questionnaires; and those who did not want to participate in the study.

This study was approved by the Research Ethics Committee of the Maurício de Nassau University Center, protocol number 2.284.118. All participants had voluntarily agreed to participate and signed Free Informed Consent Forms.

Data collection occurred during individual interviews with the participants, which lasted about $30 \mathrm{~min}$, in a calm, reserved, and appropriate location. All questions were explained to the interviewees by two trained interviewers. Initially, a semi-structured questionnaire was employed, with open-ended and closed-ended questions, to obtain personal information from the participants: name, telephone number and address, socioeconomic history including age (stratified according to the age groups defined by the Brazilian Institute of Geography and Statistics, (IBGE)), Body Mass Index (BMI), race, marital status, education level, family income as stratified by the Brazilian government in terms of the minimum wage in 2017, access to health services, life habits (consumption of tobacco or alcohol, and the frequency of physical activity), obstetric history (number of pregnancies and births), presence of comorbidities or multimorbidities (diabetes, systemic arterial pressure, arthritis/arthrosis), use of medications, type of UI, dizziness and loss of balance during ADL (have you felt dizzy or lost your balance in daily activities?), falls due to dizziness or loss of balance during ADL (have you fallen due to dizziness or loss of balance during daily activities?), proportion of restful sleep (little, moderate, complete), and occurrence of sleep disruption from having to urinate during the night (nocturia). The criteria to evaluate the practice of physical activity were based on the questions within Module P-Lifestyles, from the questionnaire of National Health Research, which addresses research involving participants from the Brazilian population [16]. According to this questionnaire, physically active women were defined as those who practiced any type of physical exercise or sport in the last three months (not considering physiotherapy). All questions were answered based on self-reporting by the interviewee. The aforementioned variables are organized in Tables 1 and 2.

Measurement of UI employed the International Consultation Incontinence Questionnaire Short Form (ICIQ-SF). This questionnaire consists of four questions that assess the frequency and amount of urine loss (evaluated by two different questions). The ICIQ-SF score is obtained by adding the answers to questions 3,4 , and 5 of the questionnaire, and varies between 0 and 21 points. The higher the score, the higher the severity and impact of UI on QL [17]. Based on the score, the questionnaire quantifies the impact of UI on QL, and is divided into no incontinence ( 0 points), slight impact (1-5 points), moderate impact (6-12 points), severe impact (13-18 points), and very severe impact (19-21 points) [17]. Finally, the situations during which urine losses occur were investigated, such as during the practice of physical exercise, or when coughing or sneezing, and encompassed a set of eight items for self-diagnosis, related to the causes or UI situations experienced by participants $[17,18]$.

The information collected with the questionnaires was organized in a databank. Statistical analysis employed software Stata 13.0 (StataCorp LLC, College Station, TX, USA). For the quantitative variables, data adequacy to the normal distribution was assessed by considering established criteria: minimum and maximum values contained within the interval corresponding to the mean value \pm three standard deviations (SD), and modules of kurtosis and asymmetry lower than twice their corresponding SD. Initially, results were presented by descriptive statistics, with tables for absolute and relative data. Then bivariate analysis was carried out, using Pearson's chi-squared test or Fisher's Exact test. The magnitude of the association was verified by the prevalence ratio, to a confidence level of $95 \%$, for each of the independent categorical nominal variables concerning a dependent variable. Multivariate analysis was developed to identify the factors associated with UI, employing Poisson's regression with robust variance to a confidence level of $95 \%$. Different theoretical models were analyzed, including all the variables that presented $p>0.05$ in the bivariate 
analysis. These variables were tested and included or excluded according to theoretical plausibility and collinearity. In addition, some variables were tested in the multivariate analysis as adjustment variables (i.e., age, number of births or number of pregnancies, mode of delivery) due to their theoretical significance.

\section{Results}

The study included 106 older women who practiced physical activity, with ages varying from 60 to 88 years, averaging $69.1 \pm 5.69$. The frequency of physical exercise was $3.76 \pm 1.49$ times a week. The main characteristics of the sample were: predominantly white race, eutrophic or overweight, married or living with a partner, who finished high school, with an income between 1 and 2 minimum wages (class E), with access to health services through private health plans, and who mostly did not smoke tobacco or drink alcoholic beverages. Regarding the clinical data of the sample, most did not present intestinal constipation and had experienced on average $3 \pm 2.16$ pregnancies and $2 \pm 2.03$ births. Concerning comorbidities, arterial hypertension was highlighted, along with nocturia, and $54.7 \%$ presented UI (95\% CI: 63.3-461), of which stress incontinence (SI) was most common.

Among the older women interviewed, the ICIQ score varied between 0 and 17 points, with an average of $3.87 \pm 4.87$. The majority did not experience any negative impacts on QL. Table 1 shows the description of these data.

Table 1. Description of participants. Natal/Brazil, 2020.

\begin{tabular}{|c|c|c|}
\hline & $N$ & $\%$ \\
\hline \multicolumn{3}{|l|}{ Age } \\
\hline 60-69 years old & 60 & 56.6 \\
\hline 70-79 years old & 40 & 37.7 \\
\hline 80 years old and over & 6 & 5.7 \\
\hline \multicolumn{3}{|l|}{ Body Mass Index } \\
\hline Underweight (up to 18.5) & 2 & 1.9 \\
\hline Eutrophic (18.5-24.9) & 34 & 32.1 \\
\hline Overweight (25.0-29.9) & 40 & 37.7 \\
\hline Obese ( 30.0 or more) & 30 & 28.3 \\
\hline \multicolumn{3}{|l|}{ Ethnicity/Race } \\
\hline While & 56 & 52.8 \\
\hline Parda & 40 & 37.7 \\
\hline Black & 10 & 5.9 \\
\hline \multicolumn{3}{|l|}{ Marital status } \\
\hline Single & 17 & 16.0 \\
\hline Married/Living with partner & 42 & 39.6 \\
\hline Divorced & 16 & 15.1 \\
\hline Widow & 31 & 29.2 \\
\hline \multicolumn{3}{|l|}{ Education level } \\
\hline Illiterate & 4 & 3.8 \\
\hline Incomplete fundamental level & 19 & 17.9 \\
\hline Complete fundamental level & 18 & 17.0 \\
\hline Incomplete secondary level & 13 & 12.3 \\
\hline Complete secondary level & 34 & 32.1 \\
\hline $\begin{array}{l}\text { Complete graduate level } \\
\text { Income }\end{array}$ & 18 & 17.0 \\
\hline 1-2 minimum wages & 58 & 54.7 \\
\hline 3-4 minimum wages & 27 & 25.5 \\
\hline$>4$ minimum wages & 14 & 13.2 \\
\hline Not informed & 7 & 6.6 \\
\hline \multicolumn{3}{|l|}{ Access to health services } \\
\hline Public & 48 & 45.3 \\
\hline Private & 56 & 52.8 \\
\hline No answer & 2 & 1.9 \\
\hline
\end{tabular}


Table 1. Cont.

\begin{tabular}{|c|c|c|}
\hline & $N$ & $\%$ \\
\hline \multicolumn{3}{|l|}{ Consumption of tobacco } \\
\hline Yes & 8 & 7.5 \\
\hline No & 98 & 92.5 \\
\hline \multicolumn{3}{|l|}{ Consumption of alcohol } \\
\hline Yes & 21 & 19.8 \\
\hline No & 85 & 80.2 \\
\hline \multicolumn{3}{|l|}{ Constipation } \\
\hline Yes & 39 & 36.8 \\
\hline No & 67 & 63.2 \\
\hline \multicolumn{3}{|l|}{ Number of pregnancies } \\
\hline Up to 1 & 19 & 17.9 \\
\hline 2 or more & 87 & 82.1 \\
\hline \multicolumn{3}{|l|}{ Number of births } \\
\hline Up to 1 & 22 & 20.8 \\
\hline 2 or more & 84 & 79.2 \\
\hline \multicolumn{3}{|l|}{ Mode of delivery } \\
\hline Vaginal delivery & 49 & 46.2 \\
\hline Cesarean delivery & 17 & 16.0 \\
\hline Both (vaginal and cesarean delivery) & 28 & 26.4 \\
\hline \multicolumn{3}{|l|}{ Comorbidities } \\
\hline Diabetes & 19 & 17.9 \\
\hline Hypertension & 37 & 34.9 \\
\hline Arthritis/Arthrosis & 36 & 34.0 \\
\hline Others & 1 & 0.9 \\
\hline None & 13 & 12.3 \\
\hline \multicolumn{3}{|l|}{ Multimorbidity } \\
\hline 2 or more chronic diseases & 53 & 50.0 \\
\hline 1 chronic disease & 40 & 37.7 \\
\hline None & 13 & 12.3 \\
\hline \multicolumn{3}{|l|}{ Medication } \\
\hline Yes & 90 & 84.9 \\
\hline Noo & 16 & 15.1 \\
\hline \multicolumn{3}{|l|}{ Restful sleep } \\
\hline Little & 31 & 29.2 \\
\hline Moderate & 33 & 31.1 \\
\hline Complete & 42 & 39.6 \\
\hline \multicolumn{3}{|l|}{ Dizziness and loss of balance during } \\
\hline \multicolumn{3}{|l|}{ ADL } \\
\hline Yes & 42 & 39.6 \\
\hline No & 64 & 60.4 \\
\hline \multicolumn{3}{|l|}{$\begin{array}{c}\text { Falls due to dizziness or loss of balance } \\
\text { during ADL }\end{array}$} \\
\hline Yes & 16 & 15.1 \\
\hline No & 90 & 84.9 \\
\hline \multicolumn{3}{|l|}{ Urinary Incontinence } \\
\hline Yes & 58 & 54.7 \\
\hline No & 48 & 45.3 \\
\hline \multicolumn{3}{|l|}{ Type of Urinary Incontinence } \\
\hline Stress UI & 43 & 40.6 \\
\hline Urge UI & 11 & 10.4 \\
\hline Mixed UI & 4 & 3.8 \\
\hline No IU & 48 & 45.3 \\
\hline \multicolumn{3}{|l|}{ Waking up frequently during the night } \\
\hline Yes & 67 & 63.2 \\
\hline No & 39 & 36.8 \\
\hline
\end{tabular}


Table 1. Cont.

\begin{tabular}{ccc}
\hline & $N$ & $\%$ \\
\hline Reason for waking up during the night & 32 & 30.2 \\
None & 3 & 2.8 \\
Change sleep position & 58 & 54.7 \\
Use bathroom & 2 & 1.9 \\
Noise & 10 & 9.4 \\
Other & 1 & 0.9 \\
No answer & & \\
ICIQ-SF & 23 & 21.7 \\
Slight impact (1 to 5 points) & 29 & 27.4 \\
Moderate impact (6 to 12 points) & 6 & 5.7 \\
Severe impact (13 to 18 points) & 0 & 0.0 \\
Very severe impact (19 to 21 points) & 0 & \\
\hline ADL: activities of daily living. ICIQ-SF: International Consultation Incontinence Questionnaire Short Form.
\end{tabular}

Regarding the bivariate analysis of the socioeconomic variables and clinical records, for physically active older women with UI, data presented a statistically significant association with education levels, medications, dizziness and loss of balance during ADL, and waking up during the night (Table 2).

Table 2. Bivariate analysis between socioeconomic characteristics, clinical records, and urinary incontinence in older women who practice physical exercise. Natal, Brazil 2020.

\begin{tabular}{|c|c|c|c|c|c|c|c|}
\hline \multicolumn{8}{|c|}{ Urinary Incontinence } \\
\hline & \multicolumn{2}{|c|}{ Present } & \multicolumn{2}{|c|}{ Absent } & \multirow{2}{*}{$p$} & \multirow{2}{*}{ PR } & \multirow{2}{*}{ CI $(95 \%)$} \\
\hline & $n$ & $\%$ & $n$ & $\%$ & & & \\
\hline \multicolumn{8}{|l|}{ Age } \\
\hline 80 or more & 4 & 66.6 & 2 & 33.3 & \multirow{3}{*}{0.479} & 1.14 & \multirow{3}{*}{$\begin{array}{l}0.55-1.20 \\
0.62-2.09\end{array}$} \\
\hline $70-79$ years old & 19 & 47.5 & 21 & 52.5 & & 0.81 & \\
\hline 60-69 years old & 35 & 58.3 & 25 & 41.6 & & 1 & \\
\hline \multicolumn{8}{|l|}{ Ethnicity/Race } \\
\hline Other & 32 & 64.0 & 18 & 36.0 & \multirow{2}{*}{0.073} & 1.37 & \multirow[b]{2}{*}{$0.96-1.95$} \\
\hline White & 26 & 46.4 & 30 & 53.6 & & 1 & \\
\hline \multicolumn{8}{|l|}{ Marital status } \\
\hline Other & 35 & 54.7 & 29 & 45.3 & \multirow{2}{*}{0.994} & 0.99 & \multirow[b]{2}{*}{$0.69-1.42$} \\
\hline Married & 23 & 54.8 & 19 & 45.2 & & 1 & \\
\hline \multicolumn{8}{|l|}{ Education level } \\
\hline Iliterate/primary & 28 & 68.3 & 13 & 31.7 & \multirow{3}{*}{0.023 * } & 1.47 & \multirow{2}{*}{$1.05-2.07$} \\
\hline Secondary/Graduate studies & 30 & 46.2 & 35 & 53.8 & & 1 & \\
\hline \multicolumn{7}{|l|}{ Access to health services } & \\
\hline Public & 31 & 62.0 & 19 & 38.0 & \multirow[t]{2}{*}{0.158} & 1.28 & \multirow[t]{2}{*}{$0.90-1.82$} \\
\hline Private & 27 & 48.2 & 29 & 51.8 & & 1 & \\
\hline \multicolumn{8}{|l|}{ BMI } \\
\hline Overweight/Obese & 37 & 52.9 & 33 & 47.1 & \multirow[t]{2}{*}{0.587} & 0.90 & \multirow[t]{2}{*}{$0.63-1.29$} \\
\hline Underweight/eutrophic & 21 & 58.3 & 15 & 41.7 & & 1 & \\
\hline \multicolumn{8}{|l|}{ Number of pregnancies } \\
\hline 2 or more & 51 & 58.6 & 36 & 41.4 & \multirow{2}{*}{0.237} & 2.05 & \multirow{2}{*}{$0.62-6.75$} \\
\hline Up to 1 & 2 & 28.6 & 5 & 71.4 & & 1 & \\
\hline \multicolumn{8}{|l|}{ Number of births } \\
\hline 2 or more & 49 & 58.3 & 35 & 41.7 & & 1.45 & \\
\hline Up to 1 & 4 & 40.0 & 6 & 60.0 & 0.346 & 1 & $0.66-3.19$ \\
\hline Mode of delivery & & & & & & & \\
\hline vaginal delivery & 28 & 57.1 & 21 & 42.9 & & 0.97 & $0.60-1.55$ \\
\hline both (vaginal and cesarean delivery) & 15 & 53.6 & 13 & 46.4 & 0.142 & 0.91 & $0.52-1.54$ \\
\hline cesarean delivery & 10 & 58.8 & 7 & 41.2 & & 1 & $0.39-0.87$ \\
\hline Multimorbidity & & & & & & & \\
\hline 1 or more chronic diseases & 53 & 57.0 & 40 & 43.0 & 0.280 & 1.48 & $0.72-3.02$ \\
\hline No chronic diseases & 5 & 38.5 & 8 & 61.5 & & 1 & \\
\hline
\end{tabular}


Table 2. Cont.

\begin{tabular}{|c|c|c|c|c|c|c|c|}
\hline \multicolumn{8}{|c|}{ Urinary Incontinence } \\
\hline & \multicolumn{2}{|c|}{ Present } & \multicolumn{2}{|c|}{ Absent } & \multirow{2}{*}{$p$} & \multirow{2}{*}{ PR } & \multirow{2}{*}{ CI $(95 \%)$} \\
\hline & $n$ & $\%$ & $n$ & $\%$ & & & \\
\hline \multicolumn{8}{|l|}{ Medications } \\
\hline Yes & 46 & 51.1 & 44 & 48.9 & $0.031 *$ & 0.68 & $0.48-0.96$ \\
\hline No & 12 & 75.0 & 4 & 25.0 & & 1 & \\
\hline \multicolumn{8}{|l|}{ Constipation } \\
\hline Yes & 22 & 56.4 & 17 & 43.6 & 0.789 & 1.04 & $0.73-1.49$ \\
\hline No & 36 & 53.7 & 31 & 46.3 & & 1 & \\
\hline \multicolumn{8}{|c|}{ Consumption of tobacco } \\
\hline Yes/ex-smoker & 5 & 33.3 & 10 & 66.7 & 0.139 & 0.57 & $0.27-1.19$ \\
\hline No & 53 & 58.2 & 38 & 41.8 & & 1 & \\
\hline \multicolumn{8}{|c|}{ Consumption of alcohol } \\
\hline Yes & 11 & 53.4 & 10 & 47.6 & 0.815 & 0.94 & $0.60-1.48$ \\
\hline No & 47 & 55.3 & 38 & 44.7 & & 1 & \\
\hline \multicolumn{8}{|c|}{ Dizziness and loss of balance during ADL } \\
\hline Yes & 30 & 71.4 & 12 & 28.6 & $0.005 *$ & 1.63 & $1.16-2.29$ \\
\hline No & 28 & 43.7 & 36 & 56.3 & & 1 & \\
\hline \multicolumn{8}{|c|}{$\begin{array}{c}\text { Falls due to dizziness or loss of balance } \\
\text { during ADL }\end{array}$} \\
\hline Yes & 11 & 68.7 & 5 & 31.3 & 0.164 & 1.31 & $0.89-1.93$ \\
\hline No & 47 & 52.2 & 43 & 47.8 & & 1 & \\
\hline \multicolumn{8}{|c|}{ Wakes up frequently during the night } \\
\hline Yes & 44 & 65.7 & 23 & 34.3 & 0.009 * & 1.82 & $1.15-2.88$ \\
\hline No & 14 & 35.9 & 25 & 64.1 & & 1 & \\
\hline
\end{tabular}

${ }^{*}$ significant for $p<0.05$; BMI: Body Mass Index.

In multivariate analysis, after testing all the variables differently, the proposed model demonstrated that the prevalence of UI was higher among women with dizziness/loss of balance (PR 1.48; CI 1.06-2.07) and who wake up during the night (PR 1.63; CI 1.05-2.55). This result was established after adjusting the model for education level and the number of births (Table 3).

Table 3. Non-adjusted and adjusted prevalence and prevalence ratios for UI in older women who practice physical activities.

Natal, Brazil, 2020.

\begin{tabular}{|c|c|c|c|c|c|c|c|c|c|c|}
\hline & \multicolumn{10}{|c|}{ Urinary Incontinence } \\
\hline & \multicolumn{2}{|c|}{ Absent } & \multicolumn{2}{|c|}{ Present } & \multicolumn{2}{|c|}{ Non-Adjusted } & \multicolumn{4}{|c|}{ Adjusted } \\
\hline & $N$ & $\%$ & $n$ & $\%$ & $p$ & PR & CI (95\%) & $p$ & PR & CI $(95 \%)$ \\
\hline Dizziness and loss of balance during ADL & & & & & & & & & & \\
\hline $\begin{array}{c}\text { Yes } \\
\text { Whelo }\end{array}$ & 12 & 28.6 & 30 & 71.4 & 0.005 & 1.63 & $1.16-2.29$ & 0.006 & 1.63 & $1.15-2.30$ \\
\hline $\begin{array}{l}\text { Wake up rrequently auring the nignt } \\
\text { Yes }\end{array}$ & 23 & 34.3 & 44 & 65.7 & 0.009 & 1.82 & $1.15-2.88$ & 0.030 & 1.70 & $1.05-2.76$ \\
\hline Education level & & & & & & & & & & \\
\hline Illiterate/primary & 13 & 31.7 & 28 & 68.3 & 0.023 & 1.47 & $1.05-2.07$ & 0.483 & 1.12 & $0.80-1.57$ \\
\hline 2 or more & 35 & 41.6 & 53 & 56.4 & 0.346 & 1.30 & $0.66-3.19$ & 0.573 & 1.37 & $0.45-4.21$ \\
\hline
\end{tabular}

PR: Prevalence ratio; CI: Confidence interval.

\section{Discussion}

This study evaluated the factors associated with UI in older women who practiced regular PA. Regarding UI, the participants presented a high prevalence for this dysfunction, mainly stress incontinence. Dizziness/loss of balance and waking up at night (sleep disruption) were significantly associated with a higher prevalence of UI in the sample, and was independent of education levels and the number of births. Strategies directed to the prevention and care throughout the life of these active seniors could have a substantial 
effect on these findings. Although PA is a protection factor for several health outcomes, including UI [18], other biological, psychological, social, and cultural aspects can lead to this issue in the female older population [19]. It must be noted that aspects related to the aging process can lead to the reduction of periurethral fibers and consequently to a decrease in urethral closure pressure, which leads to urine losses, especially during increases in intra-abdominal pressure [13]. Previous studies in developed countries found a UI prevalence of $27.5-28.0 \%$ among physically active female older people $[20,21]$. These results were lower than those obtained herein, which is possibly due to other factors that diverged between the study samples, such as the higher education levels of participants in developed countries. Researchers have highlighted the impact of social determinants (such as education levels) on people's health, as better health-related indicators are frequently associated with higher levels of education [22,23]. Nevertheless, more studies are required on the direct evaluation of social determinants of health and the relationship between physical activity levels and UI.

It was verified that waking up during the night is related to UI in physically active older women. The main reason reported for sleep disruption, was having to urinate during the night, which refers to nocturia (one of the urinary symptoms of urge or mixed UI, in the study participants) [24].

Factors associated with nocturia include a decrease in bladder capacity, an increase of urine production during the night, sleep disorders, and even the time spent in bed [25]. Although PA presents a critical positive impact on the quality of sleep of older people [26], sleep quality can be negatively affected in seniors who suffer from UI, despite the benefits of the regular practice of physical activities [27,28].

Faria, Menezes, Rodrigues, Ferreira, \& Bolsas (2014), reported a relationship between nocturia and chronic issues such as diabetes, sleep apnea, kidney disease, and hypertension. Some of these factors are present in our sample and could have contributed to the results [29]. The presence of nocturia and urine losses can be triggered by medications commonly indicated for these comorbidities, such as diuretics [29]. These medications increase urine production, urinary frequency, and cause an overload of bladder capacity, which generate urge-related urine losses [30]. Another factor that relates UI and the use of medications involves using anti-hypertension drugs such as alpha-blockers, which relax the smooth urethral muscle, contributing to UI [31].

The use of medications has been described in scientific literature as a risk factor for UI, however, with the model utilized, the present study did not establish a significant relationship. Nevertheless, the use of medications and their combined use in the presence of multimorbidity can contribute to different types of UI in older women. This corroborates the higher presence of urge- and mixed-UI in the studied population, and multimorbidity. Older adults are usually affected by multiple chronic diseases and generally use medications [32]. Practicing regular PA can help control these issues, mitigating signs, symptoms, and functional deterioration of these pathologies [32], and reducing the use or dosage of medication [33]. The presence of chronic diseases is multifactorial and must be assessed carefully in older age groups.

Besides sleep disruption, dizziness and loss of balance during ADL were also associated with the presence of UI in physically active older women. Physiological mechanisms and aspects of the environmental context can influence this association. One of the hypotheses for this association is that, biomechanically, women with UI use the hip adductor muscles to substitute for the pelvic floor muscles as a strategy to prevent urine losses. This overburden on the synergist muscles, considered as secondary motor muscles, can lead to a failure of the hip in maintaining balance. There is less lateral support, causing imbalance due to a minimized strategy of the hip to recover balance [34]. Moraes et al. (2018) remark that the older population is more vulnerable. As years progress, there can be a loss of strength and resistance, reducing physiological function, which decreases sensorial perception and leads to loss of balance $[35,36]$. 
Rosa and Braz (2016) carried out an integrative review that analyzed the risk of falls in older people with UI, and found an increased risk in this age group, especially when getting up to use the bathroom. External factors, such as lighting, the type of floor, and obstacles throughout the house, can be involved in the process of getting up from bed to use the bathroom and loss of balance during ADL [37].

The hypotheses considered herein on the relationships between UI, falls and loss of balance, can have significant clinical implications in the selection of strategies for the professional care of older people. These findings can enable more specific actions to be directed to the promotion, prevention, diagnosis, care, and rehabilitation of older adults that experience loss of balance and UI, which can prevent falls and their negative consequences.

On the number of births, scientific literature has extensive documentation that birth can increase the risk of UI. During birth, the pelvic floor muscles are subject to a fetal cephalic diameter four times larger than the urogenital diameter, which entails excessive stretching of the pelvic floor muscles during expulsion, leading to traumas and/or spontaneous perineal lacerations as well as episiotomy [38]. Physiological and anatomic adaptations during birth can cause changes to the functions of the pelvic floor muscles, decreasing muscle strength as well as control, coordination, tonus, resistance, and causing reflex-dysfunctions in the pelvic floor, mainly UI [39,40].

The coordination of voluntary movement is one of the functions of the musculoskeletal system, which activates the correct muscles at the right time and with adequate intensity to develop a specific action, and is considered adequate when the pelvic floor contracts without involving other muscles. Impaired function occurs when synergist muscles are activated (e.g., adductors, glutes, abdominals, respiratory) or the Valsalva maneuver is employed to maintain continence $[40,41]$, which could be another factor for the presence of loss of balance in the older population. However, differently from the literature, this study demonstrated that the number of births did not influence the determination of UI, which can be explained by the low variability of the sample.

The average age of the group was over 69 years old, and the sample of older women over 80 years old consisted of only 6 participants. In this way, the results obtained herein must be interpreted with caution regarding the older age groups. Most participants were not obese (eutrophic and overweight) [42,43]. This reinforces the hypothesis of the importance of PA for weight control, even though the present study cannot provide a cause-effect relationship.

The analyses of social determinants, such as race, marital status, education level, and income, presented relevant samples in all stratification groups. The prevalence ratio assessment verified that low education levels were a risk factor for UI, although not statistically significant in the model utilized. Low levels of education can affect essential aspects, such as personal hygiene and other self-care activities of women [44]. Besides, low education levels can be related (directly or indirectly) to other important risk factors for UI: number of pregnancies, obesity, and healthy habits (diet and PA) [45]. Inter-sector public policies can promote better education and potentialize the empowerment and self-care of older women to address questions related to UI.

Some of these social determinants can be modified through public policies and better distribution of income and access to health services, and can interfere positively with older people's health [45]. Most older women did not habitually consume alcohol and did not smoke. Health habits can positively affect the overall health condition and perception of the quality of life of older adults. In the case of non-modifiable social determinants (e.g., race), the majority were white older women, which corroborates the findings of Marques et al. [45]. Positive strategies related to social support between older people are valuable resources for maintaining a good quality of life. These strategies can positively influence the management and perception of adverse outcomes in the health of seniors [46]. Broader and more complex approaches must be considered by health professionals, involving social determinants in the care of older adults. 
On the limitations of this study, due to its cross-sectional methodological design, no conclusions can be drawn related to causality, only to association; which reflects the clinical implications on the management and elaboration of assistance care programs, and construction of public policies for this age group. Despite the regular physical activity of older women, the PA intensity and duration were not measured; this hinders the determination of a more precise relationship between physical exercise and UI, or with the other evaluated parameters. Convenience sampling was used (non-probabilistic) and therefore, the application of the results obtained herein must be made with caution due to the lack of control of random error.

\section{Conclusions}

The study assessed the factors associated with urinary incontinence in active older women who participate in community groups. In physically active older women with UI, there was a significant association between waking up during the night and dizziness and loss of balance during ADL, regardless of education levels and the number of births. These findings can help build public policies for health promotion, the prevention of modifiable social determinants, and improvement of clinical programs directed to address UI in the female older population and modifiable social determinants.

Author Contributions: Conceptualization, T.S.R.G., M.B.O.G.G., J.J.-R., and D.L.B.d.S.; methodology, T.S.R.G., M.B.O.G.G., J.J.-R., and D.L.B.d.S.; data curation, T.S.R.G., H.K.M.d.O., R.L.S., and V.L.d.C.; statistical analysis; T.S.R.G., J.M.L., N.P.D.d.O., J.J.-R., and D.L.B.d.S.; writing-original draft preparation, T.S.R.G., M.B.O.G.G., and J.M.L. writing-review and editing, T.S.R.G., M.B.O.G.G., J.M.L., J.J.-R., and D.L.B.d.S.; supervision, J.J.-R. and D.L.B.d.S. All authors have read and agreed to the published version of the manuscript.

Funding: This research received no external funding.

Institutional Review Board Statement: The study was conducted according to the guidelines of the Declaration of Helsinki, and approved by the Research Ethics Committee of the Maurício de Nassau University Center, protocol number 2.284.118.

Informed Consent Statement: Informed consent was obtained from all subjects involved in the study.

Data Availability Statement: The data presented in this study are available on request from the corresponding author.

Conflicts of Interest: The authors declare no conflict of interest.

\section{References}

1. Sousa, N.F.D.S.; Lima, M.G.; Cesar, C.L.G.; Barros, M.B.D.A. Envelhecimento ativo: Prevalência e diferenças de gênero e idade em estudo de base populacional. Cad. Saúde Pública 2018, 34, e00173317. [CrossRef]

2. United Nations. World Population Prospects: Key Findings and Advance Tables; the 2017 revision; United Nations: New York, NY, USA, 2017.

3. United Nations. World Population Prospects: Key Findings and Advance Tables; the 2015 revision; United Nations: New York, NY, USA, 2015.

4. Veras, R.P.; Oliveira, M. Envelhecer no Brasil: A construção de um modelo de cuidado. Ciência Saúde Coletiva 2018, 23, 1929-1936. [CrossRef]

5. Lu, W.; Pikhart, H.; Sacker, A. Domains and Measurements of Healthy Aging in Epidemiological Studies: A Review. Gerontologist 2019, 59, e294-e310. [CrossRef]

6. World Health Organization. Active Ageing-A Policy Framework. A contribution of the World Health Organization to the Second United Nations World Assembly on Ageing; WHO: Geneva, Switzerland, 2002.

7. Roberts, C.E.; Phillips, L.H.; Cooper, C.L.; Gray, S.; Allan, J.L. Effect of Different Types of Physical Activity on Activities of Daily Living in Older Adults: Systematic Review and Meta-Analysis. J. Aging Phys. Act. 2017, 25, 653-670. [CrossRef]

8. Stenholm, S.; Koster, A.; Valkeinen, H.; Patel, K.V.; Bandinelli, S.; Guralnik, J.M.; Ferrucci, L. Association of Physical Activity History With Physical Function and Mortality in Old Age. J. Gerontol. Ser. A Boil. Sci. Med. Sci. 2016, 71, 496-501. [CrossRef] [PubMed]

9. Milsom, I.; Gyhagen, M. The prevalence of urinary incontinence. Climacteric 2019, 22, 217-222. [CrossRef] [PubMed]

10. Volkmer, C.; Monticelli, M.; Reibnitz, K.S.; Brüggemann, O.M.; Sperandio, F.F. Incontinência urinária feminina: Revisão sistemática de estudos qualitativos. Ciência Saúde Coletiva 2012, 17, 2703-2715. [CrossRef] 
11. Magaldi, C.M.; Saraiva, A.; Franciulli, P.M.; Magaldi, F.M.; Moreno, M.; Miranda, M.L.J.; Maifrino, L.B.M. The Influence of Physical Activity on Functional Performance and Urinary Incontinence in Elderly Women. J. Morphol. Sci. 2018, 35, 1-8. [CrossRef]

12. Bø, K. Urinary Incontinence, Pelvic Floor Dysfunction, Exercise and Sport. Sports Med. 2004, 34, 451-464. [CrossRef]

13. Virtuoso, J.F.; Mazo, G.Z.; Menezes, E.C. Urinary incontinence and perineal muscle function in physically active and sedentary elderly women. Braz. J. Phys. Ther. 2011, 15, 310-317. [CrossRef]

14. Fernandes, S.; Coutinho, E.; Duarte, J.; Nelas, P.; Chaves, C.; Amaral, O. Quality of life in women with Urinary Incontinence. Rev. Enferm. Ref. 2015, 4, 93-99. [CrossRef]

15. Newcombe, R.G. Interval estimation for the difference between independent proportions: Comparison of eleven methods. Stat. Med. 1998, 17, 873-890. [CrossRef]

16. Szwarcwald, C.L.; Malta, D.C.; Pereira, C.A.; Vieira, M.L.F.P.; Conde, W.L.; de Souza Júnior, P.R.B.; Damacena, G.N.; Azevedo, L.O.; Azevedo, G. National Health Survey in Brazil: Design and methodology of application. Ciência Saúde Coletiva 2014, 19, 333-342. [CrossRef]

17. Klovning, A.; Avery, K.; Sandvik, H.; Hunskaar, S. Comparison of two questionnaires for assessing the severity of urinary incontinence: The ICIQ-UI SF versus the incontinence severity index. Neurourol. Urodyn. 2009, 28, 411-415. [CrossRef] [PubMed]

18. Chu, C.M.; Khanijow, K.D.; Schmitz, K.H.; Newman, D.K.; Arya, L.A.; Harvie, H.S. Physical Activity Patterns and Sedentary Behavior in Older Women With Urinary Incontinence: An Accelerometer-based Study. Female Pelvic Med. Reconstr. Surg. 2019, 25, 318-322. [CrossRef] [PubMed]

19. Menezes, E.C.; Virtuoso, J.F.; Mazo, G.Z. Mulheres idosas com incontinência urinária apresentam menor nível de atividade física habitual. Rev. Bras. Cineantropometria Desempenho Hum. 2015, 17, 612-620. [CrossRef]

20. Lee, A.H.; Hirayama, F. Physical Activity and Urinary Incontinence in Older Adults: A Community-Based Study. Curr. Aging Sci. 2012, 5, 35-40. [CrossRef]

21. Moreno-Vecino, B.; Arija-Blázquez, A.; Pedrero-Chamizo, R.; Alcázar, J.; Gómez-Cabello, A.; Pérez-López, F.R.; GonzalezGross, M.; Casajús, J.A.; Ara, I.; EXERNET Group. Associations between obesity, physical fitness, and urinary incontinence in non-institutionalized postmenopausal women: The elderly EXERNET multi-center study. Maturitas 2015, 82, 208-214. [CrossRef]

22. Marmot, M.; Wilkinson, R.G. Social Determinants of Health, 2nd ed.; Oxford University Press: New York, NY, USA, 2011.

23. Daulhgren, G.; Whitehead, M. Polices and Strategies to Promote Social Equity in Health; Institute for Future Studies: Stockholm, Sweden, 1991.

24. Kessler, M.; Facchini, L.A.; Soares, M.U.; Nunes, B.P.; França, S.M.; Thumé, E. Prevalence of urinary incontinence among the elderly and relationship with physical and mental health indicators. Rev. Bras. Geriatr. Gerontol. 2018, 21, 397-407. [CrossRef]

25. Bliwise, D.L.; Rosen, R.C.; Baum, N. Impact of nocturia on sleep and quality of life: A brief, selected review for the International Consultation on Incontinence Research Society (ICI-RS) nocturia think tank. Neurourol. Urodyn. 2014, 33, S15-S18. [CrossRef]

26. Reis, R.B.; Cologna, A.J.; Martins, A.C.P.; Tucci, S., Jr.; Suaid, H.J. Incontinência urinária no idoso. Acta Cirúrgica Bras. 2003, 18, 47-51. [CrossRef]

27. Ceolim, M.F.; Menna-Barreto, L. Sleep/wake cycle and physical activity in healthy elderly people. Sleep Res. Online Sro 2000, 3 , 87-95.

28. Moreno, C.R.C.; Santos, J.L.F.; Lebrão, M.L.; Ulhôa, M.A.; Duarte, Y.A.O. Problemas de sono em idosos estão associados a sexo feminino, dor e incontinência urinária. Rev. Bras. Epidemiol. 2018, 21 (Suppl. 2), e180018. [CrossRef]

29. Faria, C.A.; De Menezes, A.M.N.; Rodrigues, A.O.; Ferreira, A.D.L.V.; Bolsas, C.D.N. Incontinência urinária e noctúria: Prevalência e impacto sobre qualidade de vida em idosas numa Unidade Básica de Saúde. Rev. Bras. Geriatr. Gerontol. 2014, 17, 17-25. [CrossRef]

30. Panesar, K. Drug-Induced Urinary Incontinence. Us Pharm. 2014, 39, 24-29.

31. Ruby, C.M.; Hanlon, J.T.; Boudreau, R.; Newman, A.B.; Simonsick, E.M.; Shorr, R.I.; Bauer, D.C.; Resnick, N.M. The Effect of Medication Use on Urinary Incontinence in Community-Dwelling Elderly Women. J. Am. Geriatr. Soc. 2010, 58, 1715-1720. [CrossRef] [PubMed]

32. Reigota, R.B.; Pedro, A.O.; Machado, V.D.S.S.; Costa-Paiva, L.; Pinto-Neto, A.M. Prevalence of urinary incontinence and its association with multimorbidity in women aged 50 years or older: A population-based study. Neurourol. Urodyn. 2016, 35, 62-68. [CrossRef] [PubMed]

33. Pimenta, F.B.; Pinho, L.; Silveira, M.F.; Botelho, A.C.C. Fatores associados a doenças crônicas em idosos atendidos pela Estratégia de Saúde da Família. Ciência Saúde Coletiva 2015, 20, 2489-2498. [CrossRef]

34. Shumway-Cook, A.; Woollacott, M.H. Controle Motor Teoria e Aplicações Praticas, 2nd ed.; Manole: Barueri, Brazil, 2003.

35. Moraes, D.C.; Lenardt, M.H.; Mello, B.H.; Setoguchi, L.S.; Lima, P.; Setlik, C.M. Instabilidade postural e a condição de fragilidade física em idosos: Revisão integrativa. Ciência Cuid. Saúde 2018, 17. [CrossRef]

36. De Sousa, J.G.; Ferreira, V.R.; De Oliveira, R.J.; Cestari, C.E. Avaliação da força muscular do assoalho pélvico em idosas com incontinência urinária. Fisioter. Mov. 2011, 24, 39-46. [CrossRef]

37. Rosa, T.S.M.; Braz, M.M. Risco de quedas em idosos com incontinência: Uma revisão integrativa. Rev. Kairós Gerontol. 2016, 19, 161-173. [CrossRef]

38. Ashton-Miller, J.A.; DeLancey, J.O. On the Biomechanics of Vaginal Birth and Common Sequelae. Annu. Rev. Biomed. Eng. 2009, 11, 163-176. [CrossRef] 
39. Sangsawang, B.; Sangsawang, N. Stress urinary incontinence in pregnant women: A review of prevalence, pathophysiology, and treatment. Int. Urogynecol. J. 2013, 24, 901-912. [CrossRef]

40. Corrêa, L.C.A.C.; Pirkle, C.M.; Wu, Y.Y.; Vafaei, A.; Curcio, C.-L.; Câmara, S.M.A. Urinary Incontinence Is Associated With Physical Performance Decline in Community-Dwelling Older Women: Results From the International Mobility in Aging Study. J. Aging Health 2018, 31, 1872-1891. [CrossRef]

41. Vieira, G.F.; Saltiel, F.; Miranda-Gazzola, A.P.G.; Kirkwood, R.N.; Figueiredo, E.M. Pelvic floor muscle function in women with and without urinary incontinence: Are strength and endurance the only relevant functions? A cross-sectional study. Physiotherapy 2020, 109, 85-93. [CrossRef]

42. Nascimento, M.D.M.; Pereira, L.G.D.; Cordeiro, P.R.N.; Araújo, L.M.G. Comparison and agreement of criteria for the BMI classification of physically active elderly women living in the Backlands, semi-arid Region. J. Hum. Growth Dev. 2017, 27, 342-349. [CrossRef]

43. Virtuoso, J.F.; Menezes, E.C.; Mazo, G.Z. Fatores de risco para incontinência urinária em mulheres idosas praticantes de exercícios físicos. Rev. Bras. Ginecol. Obs. 2015, 37, 82-86. [CrossRef]

44. Saadia, Z. Effect of Age, Educational Status, Parity and BMI on Development of Urinary Incontinence-A Cross Sectional Study in Saudi Population. Mater. Socio Med. 2015, 27, 251-254. [CrossRef] [PubMed]

45. Marques, L.P.; Giehl, M.W.C.; Schneider, I.J.C.; Antes, D.L.; D’Orsi, E. Demographic, health conditions, and lifestyle factors associated with urinary incontinence in elderly from Florianópolis, Santa Catarina, Brazil. Rev. Bras. Epidemiol. 2015, 18, 595-606. [CrossRef]

46. Guedes, M.B.O.G.; Lima, K.C.; Caldas, C.P.; Veras, R.P. Apoio social e o cuidado integral à saúde do idoso. Physis Rev. Saúde Coletiva 2017, 27, 1185-1204. [CrossRef] 